\title{
Sol-Gel Synthesis and Characterization of Cubic Bismuth Zinc Niobium Oxide Nanopowders
}

\author{
Ganchimeg Perenlei, Peter C. Talbot, and Wayde N. Martens \\ Chemistry, Physics and Mechanical Engineering School, Science and Engineering Faculty, \\ Queensland University of Technology, Brisbane, QLD 4001, Australia
}

Correspondence should be addressed to Wayde N. Martens; w.martens@qut.edu.au

Received 26 June 2014; Accepted 12 September 2014; Published 5 November 2014

Academic Editor: Zhenhui Kang

Copyright (C) 2014 Ganchimeg Perenlei et al. This is an open access article distributed under the Creative Commons Attribution License, which permits unrestricted use, distribution, and reproduction in any medium, provided the original work is properly cited.

\begin{abstract}
Bismuth zinc niobium oxide (BZN) was successfully synthesized by a diol-based sol-gel reaction utilizing metal acetate and alkoxide precursors. Thermal analysis of a liquid suspension of precursors suggests that the majority of organic precursors decompose at temperatures up to $150^{\circ} \mathrm{C}$, and organic free powders form above $350^{\circ} \mathrm{C}$. The experimental results indicate that a homogeneous gel is obtained at about $200^{\circ} \mathrm{C}$ and then converts to a mixture of intermediate oxides at $350-400^{\circ} \mathrm{C}$. Finally, single-phased BZN powders are obtained between 500 and $900^{\circ} \mathrm{C}$. The degree of chemical homogeneity as determined by X-ray diffraction and EDS mapping is consistent throughout the samples. Elemental analysis indicates that the atomic ratio of metals closely matches a $\mathrm{Bi}_{1.5} \mathrm{ZnNb}_{1.5} \mathrm{O}_{7}$ composition. Crystallite sizes of the BZN powders calculated from the Scherrer equation are about 33-98 nm for the samples prepared at $500-700^{\circ} \mathrm{C}$, respectively. The particle and crystallite sizes increase with increased sintering temperature. The estimated band gap of the BZN nanopowders from optical analysis is about $2.60-2.75 \mathrm{eV}$ at $500-600^{\circ} \mathrm{C}$. The observed phase formations and measured results in this study were compared with those of previous reports.
\end{abstract}

\section{Introduction}

Bismuth oxide based pyrochlore materials are of interest for decoupling capacitors, wireless communications, and lowfired high-frequency filter applications due to their dielectric properties. For these applications, the material is required to have a low sintering temperature and chemical compatibility with the metal electrodes such as silver or copper during cofiring. The dielectric properties of pyrochlore materials strongly depend on the chemical composition and sintering conditions [1].

One of the main representatives of bismuth oxide based pyrochlore compounds is bismuth zinc niobium oxide, $\mathrm{Bi}_{2} \mathrm{O}_{3}-\mathrm{ZnO}-\mathrm{Nb}_{2} \mathrm{O}_{5}$ (BZN). There are two basic phases in the $\mathrm{BZN}$ system: cubic structure $\mathrm{Bi}_{1.5} \mathrm{ZnNb}_{1.5} \mathrm{O}_{7}(\alpha$ phase) and monoclinic structure $\mathrm{Bi}_{2} \mathrm{Zn}_{2 / 3} \mathrm{Nb}_{4 / 3} \mathrm{O}_{7}$ ( $\beta$ phase). Several studies have reported synthesis of various forms of cubic BZN compounds using a variety of synthetic techniques [2-4]. Conventional solid state reaction is the most commonly employed synthesis strategy to prepare both thin film and bulk crystal BZN materials $[5,6]$. This technique does not require expensive starting materials and the synthesis process is relatively simple which includes repeated mixing and heating. The main shortcoming of this procedure is that it requires high sintering temperatures (above $950^{\circ} \mathrm{C}$ ) for an extended period of time which leads to a formation of heterogeneous multiphase particles with large crystal sizes due to the lack of stoichiometric control [7].

In order to overcome this problem, a number of methods have been used to lower the sintering temperature of the BZN. Firing aids such as $\mathrm{CuO}$ and $\mathrm{SiO}_{2}-\mathrm{B}_{2} \mathrm{O}_{3}$ have been used in the $\mathrm{BZN}$ powders synthesis process which have lowered the sintering temperature to $900^{\circ} \mathrm{C}$ and $800^{\circ} \mathrm{C}$, respectively $[8,9]$. However, it has been reported that the additives may influence the properties of the final products [10].

Other synthetic techniques, generally called wetchemical, involve the reaction of precursor solutions to prepare the BZN compounds (below $800^{\circ} \mathrm{C}$ ). Depending on the precursor solutions and solvents, this technique is referred to as a metallo-organic deposition route or aqueous 
solution-gel route [11-14]. The final powders are found to be phase pure and homogeneous with smaller particle and crystallite sizes compared to those obtained by solid state reaction, as expected for lower crystallization and sintering temperatures.

The purpose of this research was to prepare chemically homogeneous, phase pure cubic BZN powders with small size at low sintering temperature. To this end, a diol-based sol-gel reaction from an alkoxide route has been successfully employed. During the synthesis process, thermal decomposition studies were carried out to determine the approximate temperature when the phase formation occurred. Crystal structure, elemental homogeneity, and crystallite sizes of the powder samples prepared at different temperatures were thoroughly studied utilizing various techniques. The band gap values of the powders were estimated from the optical absorption data to examine its photocatalytic capabilities.

\section{Experimental Procedure}

2.1. Materials. All starting materials used in this experiment were of analytical grade $(\geq 99.9 \%)$, purchased from Aldrich (Australia), and used according to the required stoichiometric ratio to prepare cubic BZN structure. Our synthesis process was adapted from the method reported by Singh et al. [12]. Firstly, bismuth acetate $\left(\mathrm{Bi}\left(\mathrm{CH}_{3} \mathrm{COO}\right)_{3}\right)$ was added to a mixture of organic solvents consisting of 1,3-propanediol $\left(\mathrm{CH}_{2}\left(\mathrm{CH}_{2} \mathrm{OH}\right)_{2}\right)$ and dried glacial acetic acid $\left(\mathrm{C}_{2} \mathrm{H}_{4} \mathrm{O}_{2}\right)$, which was stirred at $60^{\circ} \mathrm{C}$. Subsequently, zinc acetate dihydrate $\left(\mathrm{Zn}\left(\mathrm{CH}_{3} \mathrm{COO}\right)_{2} \cdot 2 \mathrm{H}_{2} \mathrm{O}\right)$ was added to the mixture and completely dissolved at $100^{\circ} \mathrm{C}$. Niobium ethoxide $\left(\mathrm{Nb}\left(\mathrm{OC}_{2} \mathrm{H}_{5}\right)_{5}\right)$ was then added dropwise to the mixture to prevent precipitation due to its high reactivity. The mixture was continuously stirred at $60^{\circ} \mathrm{C}$ overnight. The final product obtained was a yellowish-white, translucent solution, and referred to as a liquid suspension. The synthesis was conducted in an argon glovebox due to the moisture sensitivity of alkoxide reagent. The $\mathrm{pH}$ of the mixture was adjusted to 6.0-6.5 with 1:1 ratio of organic solvents in order to achieve homogeneous polymeric gels. In subsequent experiments, the liquid suspension was slowly heated at a rate of $2^{\circ} \mathrm{C} \mathrm{min}{ }^{-1}$ and thermally treated at $350^{\circ} \mathrm{C}$ for $1 \mathrm{~h}$ in a box furnace. The sample was subdivided before further heating at $5^{\circ} \mathrm{C} \mathrm{min}^{-1}$ to enable the subdivided samples to be annealed at different temperatures in the range of $400-900^{\circ} \mathrm{C}$ for $1 \mathrm{~h}$.

2.2. Characterization. A small amount of the liquid suspension was placed on an open platinum crucible and heated from room temperature to $1000^{\circ} \mathrm{C}$ in air. A TA Instruments Q500 Thermogravimetric Analysis (TGA) was used for this experiment and a heating rate of $5^{\circ} \mathrm{C} \mathrm{min}-1$ was adopted. Infrared Emission Spectroscopy (IES) analysis was carried out on a Nicolet Nexus FTS-60A FTIR spectrometer modified via replacement of the infrared source with an emission cell. A small amount of sample was placed on the top of a platinum nail surface in a nitrogenpurged cell during heating. Temperature control of $\pm 2^{\circ} \mathrm{C}$ at the operating temperature of the samples was achieved by using a Eurotherm Model 808 proportional temperature controller attached to the thermocouple. Techniques such as $\mathrm{X}$-ray diffraction (XRD) and backscattered scanning electron microscopy (SEM) combined with Energy-dispersive X-ray spectroscopy (EDS) were used for phase determination and elemental analysis of the powder samples. XRD patterns were collected in Bragg-Brentano geometry using a Philips PANalytical X'Pert PRO X-Ray Diffractometer. The incident X-rays were produced from a PW3373/00 Co X-ray tube operating at $40 \mathrm{kV}$ and $40 \mathrm{~mA}$, providing $\mathrm{K} \alpha 1$ wavelength of $1.7903 \AA$. Diffraction patterns were collected from 5.0-90 $(2 \theta)$ with either 0.01 or 0.02 step size, on a spun stage. $\mathrm{A} \mathrm{LaB}_{6}$ standard powder was also used as a size/strain standard to calibrate instrumental broadening of diffraction peaks. Secondary electron and backscattered electron images of the surface of powder samples were captured by a Zeiss Sigma FE-SEM and EDS, operating at $20 \mathrm{kV}$. All samples were coated with gold before analysis to minimize excessive electron buildup. Elemental ratios of the samples were analyzed by Inductively Coupled Plasma with Optical Emission Spectrometers (ICPOES) analysis. A PerkinElmer Optima 8300 DV Inductively Coupled Plasma Optical Emission Spectrometer was used for this experiment. To dissolve the samples in acid, a known amount of lithium borate was mixed with powders and fused in platinum crucibles. The fusion products were then dissolved in a mixture of 5\% of nitric acid and $0.5 \%$ hydrofluoric acid. Ultraviolet and Visible (UV-Vis) was used for light absorption analysis from which the band gaps of the samples were calculated. Spectra were recorded on a UV-VisNIR Cary 5000 Stheno spectrometer in the 200 to $800 \mathrm{~nm}$ region.

\section{Results and Discussion}

Thermal analysis of a liquid suspension was started from room temperature and completed at $1000^{\circ} \mathrm{C}$. Figure 1 shows the dTG/TG analysis results. A large exothermic dTG peak were obtained at 80 and $145^{\circ} \mathrm{C}$, which corresponds to about $83 \%$ of the total mass loss. This large mass loss was due to the evaporation of water and residual organic solvents contained within the precursor solution. The thermal decomposition study revealed that two small dTG peaks were observed at about 250 and $330^{\circ} \mathrm{C}$. This slow and constant mass decay consisted of about $4 \%$ mass loss. The dTG/TG curves show that the main decomposition of the organic precursors occurred just before $150^{\circ} \mathrm{C}$ and continuously occurred until $330^{\circ} \mathrm{C}$.

This result was quite similar to Wang's reported experimental work [11]. However, there was a weak exothermic peak obtained at about $545^{\circ} \mathrm{C}$, which was not observed in this experimental result. Other authors' works on thermal decomposition of the BZN powders showed that there were significant weight losses observed above $500^{\circ} \mathrm{C}[13,14]$. From this experiment result, no other significant mass loss was observed from the TG curve as the temperature was increased up to $1000^{\circ} \mathrm{C}$, indicating limited or no volatility of bismuth or other metals. This result suggested that the majority of the organic precursors decomposed before the gel sample formed 


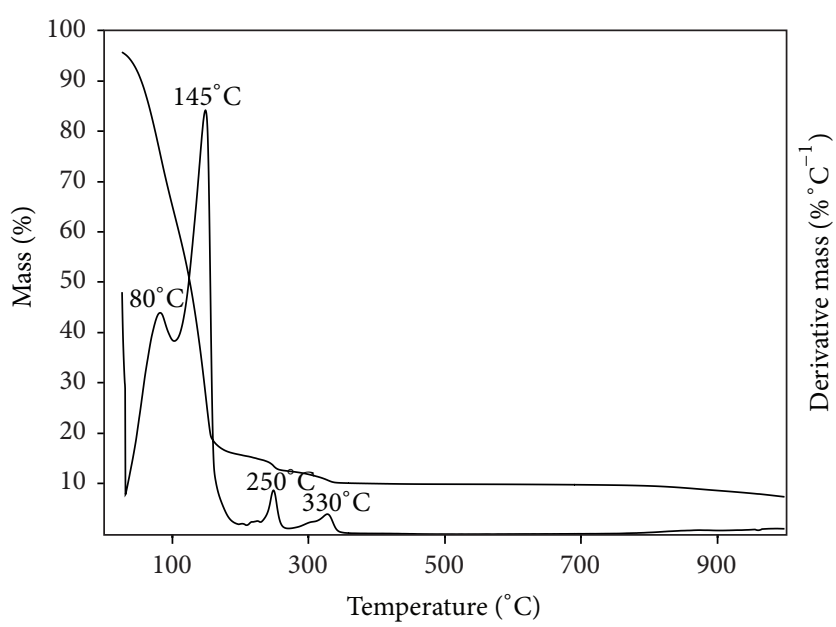

FIgURE 1: TG/dTG curves of the liquid suspension.

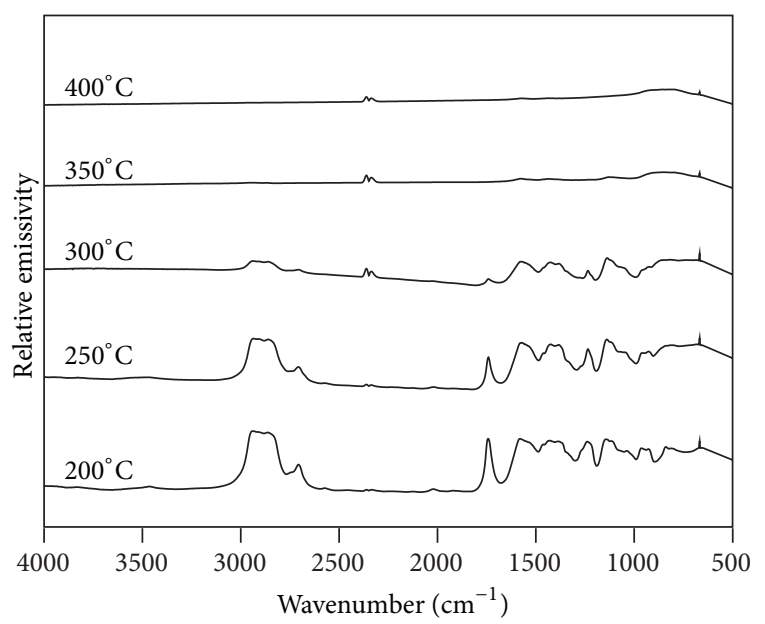

FIGURE 2: IES spectra of the liquid suspension heated from 200 to $400^{\circ} \mathrm{C}$.

at about $200^{\circ} \mathrm{C}$, and continued until $350^{\circ} \mathrm{C}$, which resulted in the formation of organic free metal oxide powders.

TGA analysis on the liquid suspension was further confirmed by IES analysis. Figure 2 shows that the sample consisted of residual organic compounds which were completely lost before the dried powder formed at $350^{\circ} \mathrm{C}$. In the IES spectra, the $\mathrm{C}-\mathrm{C}$ and $\mathrm{C}-\mathrm{O}$ stretches were observed between $1000 \mathrm{~cm}^{-1}$ and $1300 \mathrm{~cm}^{-1}$. Two peaks were also found at $2700 \mathrm{~cm}^{-1}$ and $2800 \mathrm{~cm}^{-1}$ which were due to either $-\mathrm{O}-\mathrm{CH}_{3}$ or $-\mathrm{O}-\mathrm{CH}_{2}-\mathrm{O}-$ groups. Moreover, $-\mathrm{CH}_{2}$ and $\mathrm{CH}_{3}$ bands were clearly observed in the spectra at 2850$2950 \mathrm{~cm}^{-1}$ and $1450-1475 \mathrm{~cm}^{-1}$, respectively. These were due to $\mathrm{CH}_{2}\left(\mathrm{CH}_{2} \mathrm{OH}\right)_{2}$ and $\mathrm{CH}_{3} \mathrm{COOH}$ species in the precursor solution.

As expected, when the sample was heated to $200-250^{\circ} \mathrm{C}$, the above mentioned bands were observed in the spectrum but significantly declined in intensity at $300^{\circ} \mathrm{C}$. However, the spectra were relatively featureless after the sample was heated above $350^{\circ} \mathrm{C}$, presumably due to the formation of the metal oxides. Such metal oxides were expected to show

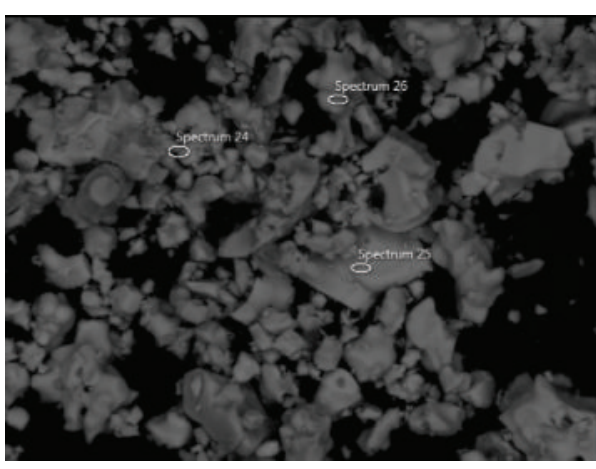

(a)

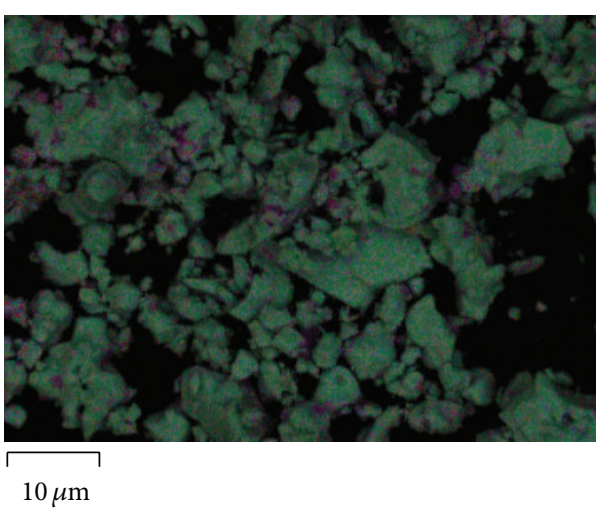

(b)

FIGURE 3: Backscattered SEM (a) and EDS mapping (b) images of the powder sample prepared at $400^{\circ} \mathrm{C}$ (Bi: blue, $\mathrm{Nb}$ : green, $\mathrm{Zn}$ : purple, and O: red).

features in their vibrational spectrum below the $500 \mathrm{~cm}^{-1}$ limit of the instrument. The IES result suggested that the organic groups from the precursors, as well as water from the reaction, completely evaporated from the liquid suspension as temperature was increased. Thus, organic free metal oxide powders formed from $350^{\circ} \mathrm{C}$ onwards. The backscattered SEM micrograph and EDS mapping images of the powder samples prepared at $400^{\circ} \mathrm{C}$ are shown in Figure 3. It can be seen from the SEM micrographs that the particles of the powders had sizes ranging from 0.5 to $3 \mu \mathrm{m}$. The SEM backscattering image in Figure 3(a) also shows some uneven elemental distribution in the sample indicating some phase separation. Elemental analysis on several areas confirmed that the bismuth and niobium atoms were not completely uniformly distributed. The EDS mapping image in Figure 3(b) also confirmed this observation. The distribution of bismuth, niobium and oxygen atoms were even throughout the sample. However, zinc atoms predominated in some areas creating small pockets of impurities. This indicated that the sample contained two or more phases; one mainly consisting of bismuth and niobium atoms, and another which was rich in zinc.

Figure 4 shows SEM micrographs and elemental mapping of the BZN powder samples prepared at $900^{\circ} \mathrm{C}$. It can be seen in Figure 4(a) that much bigger microcrystalline particles were present in this sample when compared to particles 


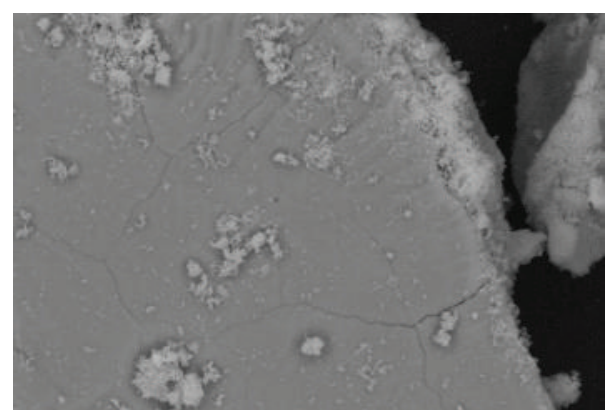

(a)

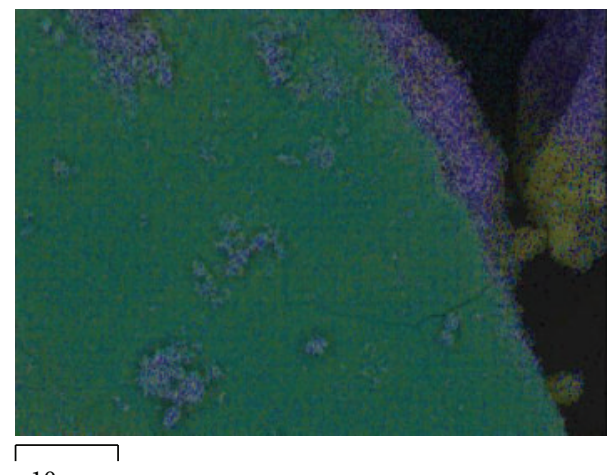

(b)

FIGURE 4: Backscattered SEM (a) and EDS mapping (b) images of the $\mathrm{BZN}$ powders prepared at $900^{\circ} \mathrm{C}$ (Bi: purple, $\mathrm{Nb}$ : light blue, and Zn: yellow).

obtained at lower temperature. Elemental distribution of each metal atom on the surface of the particles looked relatively homogeneous. However, the color differences in the EDS mapping in Figure 4(b) clearly showed the presence of small amounts of impurities. These impurities were maybe due to excess of unreacted metals such as zinc or bismuth that were rejected from the BZN particles.

XRD patterns of the powder samples prepared between 350 and $900^{\circ} \mathrm{C}$ are shown in Figure 5. The XRD pattern obtained from the sample prepared at $350^{\circ} \mathrm{C}$ indicated that the sample contained large amounts of an amorphous phase in addition to a crystalline phase. The obtained pattern matched closely that of orthorhombic bismuth niobium oxide, $\mathrm{Bi}_{7.84} \mathrm{Nb}_{0.16} \mathrm{O}_{12.16}$. The XRD pattern was unchanged when the sample was reheated at $400^{\circ} \mathrm{C}$. This suggested that two binary oxides were formed during low temperature sintering processes. ICP-OES analysis was carried out on the sample and gave as a result: $\mathrm{Bi}_{7.84} \mathrm{Nb}_{1.61} \mathrm{ZnO}_{14.786}$. The difference between the ICP-OES and the XRD pattern suggested that the amorphous phase might be niobium zinc oxide, $\mathrm{Nb}_{1.45} \mathrm{ZnO}_{2.625}$.

Phase transformation occurred as the sintering temperature was increased. Low temperature intermediate oxides directly converted to the singe-phased crystals from $500^{\circ} \mathrm{C}$ onwards. This phase was identified as cubic BZN compound (JCPDS PDF, 00-054-0971). The elemental analysis of the powder sample was carried out by ICP-OES and the

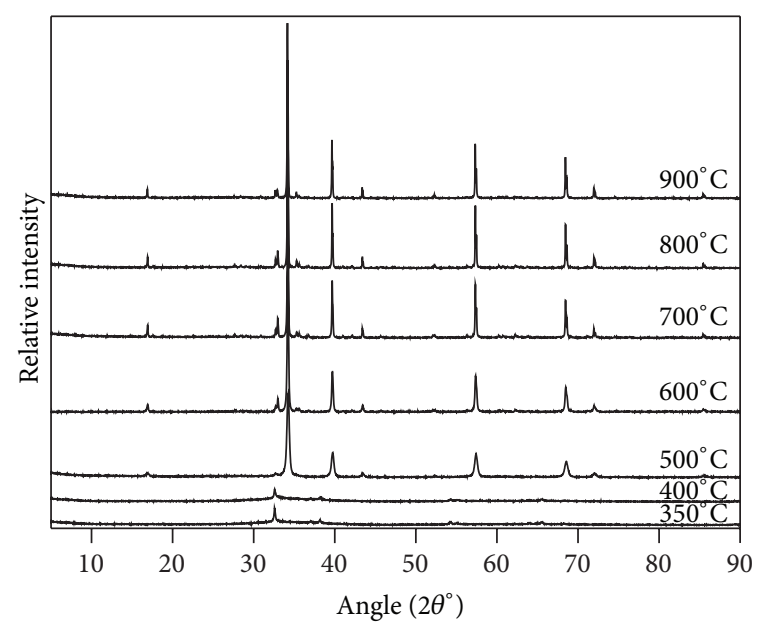

FIGURE 5: XRD patterns of the powder samples at various temperatures.

result suggested that the atomic ratio was closely matched with cubic $\mathrm{Bi}_{1.5} \mathrm{ZnNb}_{1.5} \mathrm{O}_{7}$ composition. The observed phase transformation from intermediate oxides to the singlephased BZN in this study is slightly different from those of other reported works [11-14]. The cubic BZN powders formed at $450^{\circ} \mathrm{C}$ straight from the precursor gels, and then fully crystallized at $550-600^{\circ} \mathrm{C}$ [11-14]. In another work, a small amount of residual amorphous phase was obtained besides BZN [14]. Other reports suggested that the cubic BZN phase was obtained at about $500^{\circ} \mathrm{C}[11,13]$; however, there was a small amount of $\mathrm{Bi}_{2} \mathrm{O}_{3}$ also present. This was because $\mathrm{Bi}_{2} \mathrm{O}_{3}$ phase was first formed at $400^{\circ} \mathrm{C}$ in those studies.

Nonetheless, the crystals of the BZN powder samples obtained in this study between 500 and $700^{\circ} \mathrm{C}$ were phase pure with broad peak widths, indicating small and/or disordered crystallites. The crystallite sizes of the powders were calculated from the Scherrer equation using selected diffraction peaks. The calculated sizes of the powders were 33, 72 and $98 \mathrm{~nm}$ for 500,600 and $700^{\circ} \mathrm{C}$, respectively. This result was similar with reported values of $30-90 \mathrm{~nm}$ at $450-700^{\circ} \mathrm{C}$ [11]. However, it was relatively larger than that obtained by another group reporting $13-36 \mathrm{~nm}$ at $500-700^{\circ} \mathrm{C}$ [14].

Similarly, the XRD patterns of the powders prepared at higher temperatures, $800-900^{\circ} \mathrm{C}$, were also identified as cubic BZN compound. However, small amounts of impurities were found to co-exist with the main BZN phase. Other research has suggested that the low temperature BZN phase might have a composition of $\mathrm{Bi}_{1.5} \mathrm{Zn}_{0.5} \mathrm{Nb}_{1.5} \mathrm{O}_{6.8}$ which undergoes a peritectoid decomposition at about $700^{\circ} \mathrm{C}$ to high temperature phases of $\mathrm{Bi}_{1.5} \mathrm{ZnNb}_{1.5} \mathrm{O}_{7}$ and $\mathrm{BiNbO}_{4}$ [15]. In this study, however, the small impurity observed at high temperatures corresponds to $\mathrm{ZnO}$ [16]. With increasing temperature, the peak widths significantly narrowed, indicating the formation of larger crystals.

The UV-Vis spectra of the powder samples heated at different temperatures of $350-600^{\circ} \mathrm{C}$ are shown in Figure 6. The band gaps of each sample can be estimated from the optical reflectance data to evaluate the direct transition 


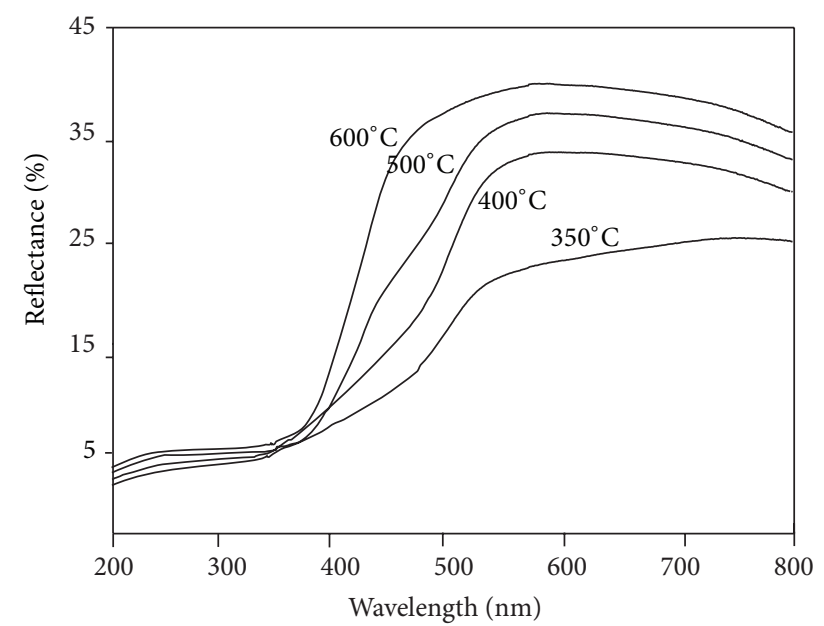

FIGURE 6: UV-Vis spectra of the powder samples at various temperatures.

between the valence band and the conduction band. Approximate band gaps of $2.25-2.29 \mathrm{eV}$ were estimated form the absorbance spectra of mixed intermediate oxides obtained at $350-400^{\circ} \mathrm{C}$. The optical band gap values estimated from extrapolation to zero of absorption versus photon energy plot, and those increased when the sample was prepared at higher temperatures.

The optical band gaps of the single-phased BZN powders formed at 500 and $600^{\circ} \mathrm{C}$ were 2.60 and $2.75 \mathrm{eV}$, respectively. This result was slightly larger than the reported value by Zanetti et al. (3.0-3.1 eV at $\left.500-700^{\circ} \mathrm{C}\right)$ [13]. The optical analysis result showed that the band gaps of the samples widened when the powders were prepared at high temperatures of above $600^{\circ} \mathrm{C}$. Such wide band gap values might be caused by the effect of bigger crystallite size due to the high sintering temperature. This study also suggests that the phase pure BZN powders have an optical absorption at wavelengths of $450 \mathrm{~nm}$, indicating that this nanostructured material can be responsive only to the UV/Vis light region.

\section{Conclusion}

A diol-based sol-gel synthesis method was successfully employed for the preparation of phase pure cubic BZN nanopowders. Thermal analysis results showed that most decomposition in the precursors occurred up to $150^{\circ} \mathrm{C}$, and it was completed before $350^{\circ} \mathrm{C}$. The results also indicated that organic free powders were obtained at $350-400^{\circ} \mathrm{C}$. Low temperature intermediate oxides were examined by elemental analysis and found to be a mixture of bismuth niobium oxide and niobium zinc oxide. These oxides then directly transformed to the single-phased BZN with increasing temperature. This finding was contrary to that of sol-gel methods in the literature, where a different phase mixture was obtained at low temperature. However, our result was similar to that reported for a solid state method, where the mixture of phases before BZN formation was comparable to ours. Measured crystallite sizes and band gaps of the BZN powders obtained from this study are in close agreement with the reported values. The optical study suggested that the BZN compound may be photoactive in the UV/Vis light region.

\section{Conflict of Interests}

The authors declare no conflict of interests regarding the publication of this paper.

\section{Acknowledgments}

The authors would like to thank Queensland University of Technology (QUT) for financial, infrastructure, and research facility support. The authors would also like to acknowledge the QUT Central Analytical Research Facility (CARF) for their assistance during the data collection. Special thanks are due to Mr. Adrian Baker, Mr. Mitchell De Bruyn, Mr. Tony Raftery, Dr. Henry Spratt, Dr. Peter Hines, Dr. Llew Rintoul, and Professor Jose Alarco for their help to complete this paper.

\section{References}

[1] Y. Hu and C.-L. Huang, "Structural characterization of Bi-ZnNb-O cubic pyrochlores," Ceramics International, vol. 30, no. 8, pp. 2241-2246, 2004.

[2] J. Singh and S. Krupanidhi, "Probing disorder in cubic pyrochlore $\mathrm{Bi}_{1.5} \mathrm{ZnNb}_{1.5} \mathrm{O}_{7}$ (BZN) thin films," Solid State Communications, vol. 150, no. 45, pp. 2257-2261, 2010.

[3] W. Liu and $\mathrm{H}$. Wang, "Sintering and dielectric properties of $\mathrm{Bi}_{1.5} \mathrm{ZnNb}_{1.5} \mathrm{O}_{7}$ cubic pyrochlore ceramics via high-energy milling technology," Journal of Electroceramics, vol. 27, no. 3-4, pp. 209-214, 2011.

[4] X. Wang, L. Yang, and J. Huang, "Effect of $\mathrm{KOH}$ concentration on the hydrothermal synthesis of $\mathrm{Bi}_{1.5} \mathrm{ZnNb}_{1.5} \mathrm{O}_{7}$ nanopowder," Electronic Components and Materials, vol. 4, p. 4, 2009.

[5] S. Kamba, V. Porokhonskyy, A. Pashkin, V. Bovtun, and J. Petzelt, "Anomalous broad dielectric relaxation in $\mathrm{Bi}_{1.5} \mathrm{Zn}_{1.0} \mathrm{Nb}_{1.5} \mathrm{O}_{7}$ pyrochlore," Physical Review B, vol. 66, no. 5, Article ID 054106, 2002.

[6] M. C. Wu, S. Kamba, V. Bovtun, and W. F. Su, "Comparison of microwave dielectric behavior between $\mathrm{Bi}_{1.5} \mathrm{Zn}_{0.92} \mathrm{Nb}_{1.5} \mathrm{O}_{6.92}$ and $\mathrm{Bi}_{1.5} \mathrm{ZnNb}_{1.5} \mathrm{O}_{7}$," Journal of the European Ceramic Society, vol. 26, no. 10-11, pp. 1889-1893, 2006.

[7] J. C. Nino, I. M. Reaney, M. T. Lanagan, and C. A. Randall, "Transmission electron microscopy investigation of $\mathrm{Bi}_{2} \mathrm{O}_{3}$ $\mathrm{ZnO}-\mathrm{Nb}_{2} \mathrm{O}_{5}$ pyrochlore and related phases," Materials Letters, vol. 57, no. 2, pp. 414-419, 2002.

[8] W. Hong, Y. Xi, and X. Feng, "Effect of $\mathrm{SiO}_{2}$ and $\mathrm{B}_{2} \mathrm{O}_{3}$ on structure and dielectric properties of $\mathrm{Bi}_{2} \mathrm{O}_{3}-\mathrm{ZnO}-\mathrm{Nb}_{2} \mathrm{O}_{5}$ based ceramics," Ferroelectrics, vol. 229, no. 1, pp. 285-290, 1999.

[9] M.-C. Wu, Y.-C. Huang, and W.-F. Su, "Silver cofirable $\mathrm{Bi}_{1.5} \mathrm{Zn}_{0.92} \mathrm{Nb}_{1.5} \mathrm{O}_{6.92}$ microwave ceramics containing $\mathrm{CuO}$ based dopants," Materials Chemistry and Physics, vol. 100, no. 2-3, pp. 391-394, 2006.

[10] W. F. Su and S. C. Lin, "Interfacial behaviour between $\mathrm{Bi}_{1.5} \mathrm{ZnNb}_{1.5} \mathrm{O} 7 \cdot 0.02 \mathrm{~V}_{2} \mathrm{O}_{5}$ and $\mathrm{Ag}$," Journal of the European Ceramic Society, vol. 23, no. 14, pp. 2593-2596, 2003.

[11] H. Wang, R. Elsebrock, T. Schneller, R. Waser, and X. Yao, "Bismuth zinc niobate $\left(\mathrm{Bi}_{1.5} \mathrm{ZnNb}_{1.5} \mathrm{O}_{7}\right)$ ceramics derived from 
metallo-organic decomposition precursor solution," Solid State Communications, vol. 132, no. 7, pp. 481-486, 2004.

[12] S. Singh, A. K. Mondal, and S. B. Krupanidhi, "Fabrication and characterization of crystalline cubic bismuth zinc niobate pyrochlore $\left(\mathrm{Bi}_{1.5} \mathrm{ZnNb}_{1.5} \mathrm{O}_{7}\right)$ nanoparticles derived by sol-gel," Advanced Science Letters, vol. 2, no. 3, pp. 356-359, 2009.

[13] S. M. Zanetti, S. A. Da Silva, and G. P. Thim, "A chemical route for the synthesis of cubic bismuth zinc niobate pyrochlore nanopowders," Journal of Solid State Chemistry, vol. 177, no. 12, pp. 4546-4551, 2004.

[14] L. Weihong, H. Wang, K. Li, M. Zhang, and X. Yao, " $\mathrm{Bi}_{1.5} \mathrm{ZnNb}_{1.5} \mathrm{O}_{7}$ cubic pyrochlore ceramics prepared by aqueous solution-gel method," Journal of Sol-Gel Science and Technology, vol. 52, no. 1, pp. 153-157, 2009.

[15] R. L. Thayer, C. A. Randall, and S. Trolier-McKinstry, "Medium permittivity bismuth zinc niobate thin film capacitors," Journal of Applied Physics, vol. 94, no. 3, pp. 1941-1947, 2003.

[16] J. C. Nino, M. T. Lanagan, and C. A. Randall, "Phase formation and reactions in the $\mathrm{Bi}_{2} \mathrm{O}_{3}-\mathrm{ZnO}-\mathrm{Nb}_{2} \mathrm{O}_{5}$-Ag pyrochlore system," Journal of Materials Research, vol. 16, no. 5, pp. 1460-1464, 2001. 

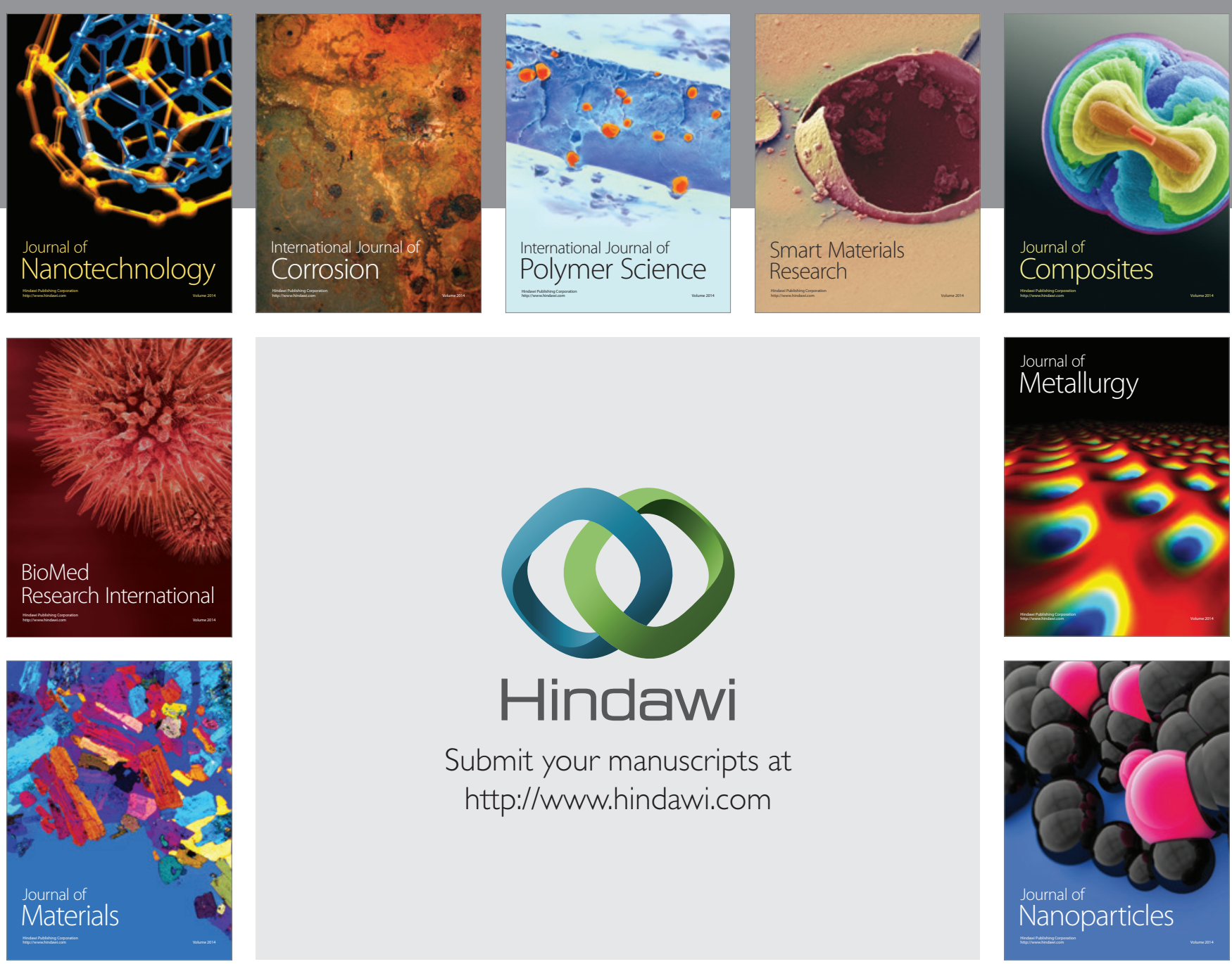

Submit your manuscripts at http://www.hindawi.com
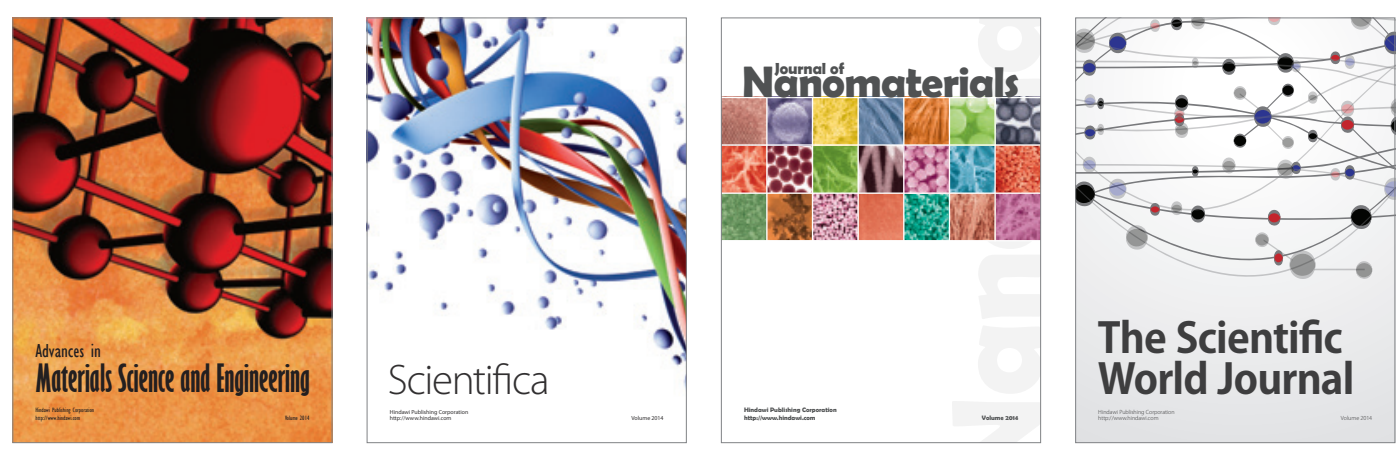

\section{The Scientific World Journal}
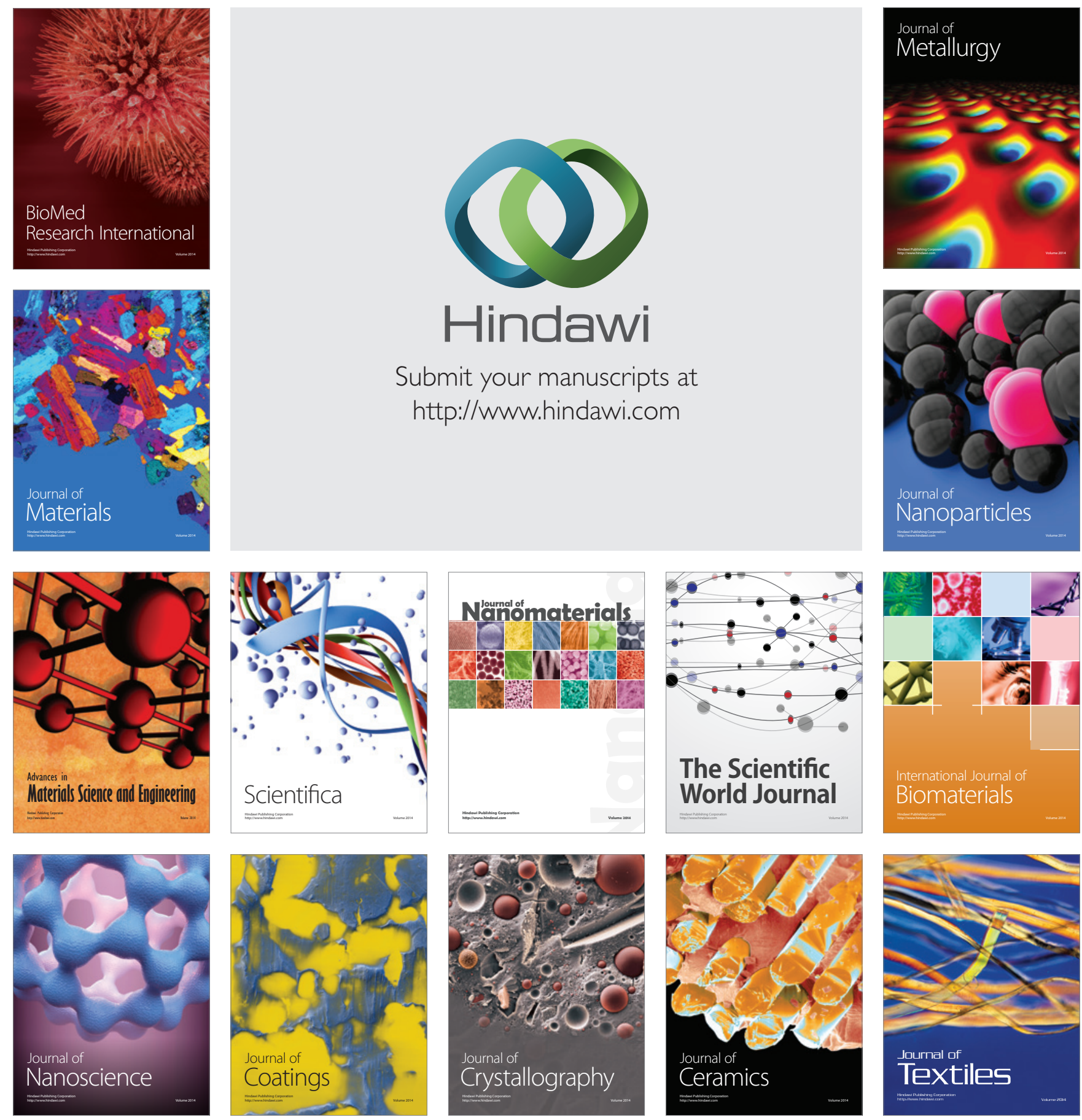